\title{
CONTEXTO FAMILIAR DE CRIANÇAS COM DEFICIÊNCIA
}

\author{
Letícia Paulina De Oliveira Massoli ${ }^{1}$ \\ Universidade do Estado de Minas Gerais \\ Stephanie Cristine Alves ${ }^{2}$ \\ Universidade do Estado de Minas Gerais \\ Marcos Venicio Esper ${ }^{3}$ \\ Universidade do Estado de Minas Gerais
}

\section{RESUMO}

A família é a primeira instituição que a criança tem contato e é a partir dela que a criança se espelha e se assemelha perante suas atitudes e valores. O nascimento de um filho vai reestruturar a formação da família, entretanto diante do diagnóstico de deficiências os pais se frustram e buscam forças para enfrentar os desafios impostos pela sociedade, devido aos reflexos dos preconceitos advindos desde a antiguidade. Na busca de enfrentarem o desafio da inclusão em sociedade, a família se torna a principal base para a criança. É nesse pensamento que se destaca a importância da família para a formação e a construção do desenvolvimento e da autonomia dessa criança perante as suas limitações. Diante disso foram realizadas entrevistas com dez famílias do município de Passos MG, a fim de analisar como as diferentes dinâmicas das estruturas familiares podem influenciar diretamente esse desenvolvimento, apresentando reflexões sobre a relação família - escola, minimizando a distância de ambas, para contribuir na evolução da criança.

Palavras-chave: Família; Deficiência; Inclusão; Pesquisa Qualitativa.

\footnotetext{
${ }^{1}$ Graduada em Pedagogia (UEMG - Universidade do Estado de Minas Gerais).

${ }^{2}$ Graduada em Pedagogia (UEMG - Universidade do Estado de Minas Gerais) e Pós graduanda em Psicopedagogia.

${ }^{3}$ Doutorando em Ciências (USP), Mestre em Ciências da Saúde (UNIFESP), Pedagogo, Psicanalista e Psicopedagogo.
} 


\section{FAMILY CONTEXT OF CHILDREN WITH DISABILITIES}

\section{ABSTRACT}

The family is the first institution that the child has contact with and it is from there that the child mirrors and resembles before their attitudes and values. The birth of a child will restructure the formation of the family, however in the face of the diagnosis of disabilities, parents are frustrated and seek strength to face the challenges imposed by society, due to the reflections of prejudices arising from antiquity. In the search to face the challenge of inclusion in society, the family becomes the main basis for the child. It is in this thought that the importance of the family for the formation and construction of the development and autonomy of this child stands out in the face of its limitations. Therefore, interviews were conducted with ten families in the municipality of Passos MG, in order to analyze how the different dynamics of family structures can directly influence this development, presenting reflections on the family-school relationship, minimizing the distance of both, to contribute to the evolution of child.

Keywords: Family; Deficiency; Inclusion; Qualitative research.

\section{Introdução}

O presente trabalho apresenta reflexões sobre a relação familiar e a visão do núcleo familiar na vida de uma criança com deficiência. Diante da análise de dez contextos familiares e suas diferentes condições buscou-se corroborar para que os profissionais que estão ligados direta e indiretamente com crianças com deficiência, se sensibilizem, a fim de contribuir para o desenvolvimento e a inclusão em sociedade, despertando a importância de mais investimentos em pesquisas desse tipo e da importância de cada pessoa ligada à criança na influência em seu desenvolvimento, devido aos reflexos do preconceito existente desde a antiguidade. Pretendeu-se, nesse trabalho, refletir sobre os principais desafios e complicações no âmbito familiar da criança com deficiência no município de Passos, no estado de Minas Gerais.

A família é a primeira instituição que trabalha a socialização para a formação da criança, desta forma a mesma desenvolve seus sentimentos, experimenta sensações, definições de certo ou errado, estimula seu progresso neuropsicomotor e é através da família que ocorre a inclusão do indivíduo na sociedade. Segundo Dessen e Polônia (2007), a família é o primeiro ambiente de socialização do indivíduo e é a primeira instituição social que procura atestar a segurança de seus sujeitos, bem como a transmissão de conceitos como empatia, religião, moral, hábitos e formas de entendimento no meio social. Sendo assim, a família tem um papel importante no comportamento de seus indivíduos, principalmente das crianças, que observam e aprendem formas de ver o mundo, encontrar-se e relacionar-se.

De acordo com Glat (1996), o nascer de uma criança ocorre muitas alterações no contexto familiar, transformando profundamente o exercício familiar, mudando os papeis sociais (marido para marido e pai, esposa para esposa e mãe, por exemplo), modificando assim a individualidade de seus integrantes e mudando as relações externas familiares, como relação de amizade e trabalho. Portanto, mesmo com as mudanças esperadas na vida das famílias, o nascer de uma criança com deficiência gera particularidades, como confusão de sentimento e dor pela ausência da criança idealizada. 
Segundo Dessen e Polônia (2007), a escola consiste em uma organização onde transmitem exercícios educativos e é um ambiente de progresso e aprendizado. Sendo assim, o currículo necessita de elaborar intervenções e experimentações considerando-se elementos como o cognitivo, cultural e social. Contudo, os conhecimentos provenientes da dinâmica familiar são mediadores na elaboração de conhecimentos científicos estimulados na escola. A escola tem como encargo social de habilitar os alunos, responsáveis e educadores, para ultrapassar dificuldades, ajudando para o progresso do indivíduo.

\section{Família e Deficiências}

O termo "pessoas com deficiência" é definido como indivíduos que apresentam qualquer tipo de empecilho capaz de dificultar ou bloquear sua atuação plena e eficiente na sociedade, seja de natureza intelectual, física ou sensorial (CONVENÇÃO, 2008, p.1). De acordo com Dias e Oliveira (2013), há três grupos principais de deficiência, sendo elas: as deficiências física, intelectual e sensorial. Em comparação às deficiências motoras e sensoriais, a deficiência de natureza intelectual manifesta-se de forma particular provocada pela invisibilidade e pelo contexto social que atribuem a esse tipo de deficiência uma cognição infantilizada, prejudicando o exercício de sua cidadania.

De acordo com Bonilha (2013), a deficiência sensorial, do ponto de vista científico, corresponde pela disfunção total ou parcial, de um ou mais dos cinco sentidos, como a surdez e a cegueira que consistem em deficiências sensoriais, como também associadas ao tato, olfato ou paladar. No ponto de vista prático a deficiência sensorial é indicada pela inabilidade de empregar os sentidos que possui, indiferente a quantidade de sentidos. Portanto, neste pensamento a deficiência sensorial não se caracteriza por ausência de um dos sentidos, mas na incapacidade de usar normalmente (DEFICIÊNCIA, 2017).

No entanto, segundo Bonilha (2013), os indivíduos que apresentam os cinco sentidos, mas não conseguem usá-los para seu bem-estar, são apontados como deficientes sensoriais. Entretanto as pessoas que obtém três ou mais dos cinco sentidos, que estão aptos de gozar em favor de uma vida produtiva, não é considerado deficiente sensorial. Já a deficiência motora, também conhecida como deficiência física, é considerada uma limitação completa ou parcial na capacidade da pessoa com esse tipo de deficiência em controlar componentes do corpo que permitem sua mobilidade.

Segundo IDMED (2014), a deficiência intelectual consiste em um termo que se usa uma vez que o indivíduo apresenta limitação no seu arcabouço mental e no empenho de atividades, tal como, na comunicabilidade, responsabilidade pessoal e socialização. Essas limitações causam dificuldade e lentidão no ato de aprender e no desenvolvimento desses indivíduos. A maior parte das crianças com deficiência intelectual assimila coisas pertinentes para a sociedade em que vivem, mas eles necessitam de mais tempo e ajuda de docentes especializados. Desta forma a criança com deficiência intelectual obtém dificuldades e atraso no seu processo neuropsicomotor, na fala e outros.

Consoante IDMED (2014), é um equívoco dizer que a deficiência intelectual é uma doença, pois não existe transmissão entre indivíduos e nem a convivência com pessoas com deficiência intelectual traz nenhum malefício para os que não obtêm a deficiência. $O$ atraso mental não consiste em uma doença mental, como transtorno depressivo, por exemplo. Sendo assim, não é necessário que o indivíduo passe por uma tentativa de cura, pois não é uma doença.

No que se diz respeito à deficiência mental, ela é entendida como um déficit do funcionamento intelectual com restrições na adaptação relacionada em no mínimo dois campos de habilidade, como no diálogo, interações interpessoais, trabalho, vida acadêmica e de independência. Todavia, na deficiência mental também há modificações na percepção da realidade da pessoa de modo que sua relação com a sociedade é afetada (IDMED 2014). 
Os transtornos mentais ou também conhecidos como doenças mentais são caracterizados por incluir um abrangente espectro de situações que interferem na mente do indivíduo. Nesse caso, os transtornos mentais causam diversos sinais e sintomas característicos, como problemas emocionais, dificuldade de memorização e falhas de conduta. A doença mental é considerada uma psicopatologia e a partir do momento que é diagnosticada por profissionais qualificados, é necessário que a pessoa seja acompanhada por uma equipe multiprofissional e especializada que atenda às suas demandas de forma inclusiva e livre de estigmatizações (IDMED 2014).

Segundo Henn, Piccinini, \& Garcia (2008), o nascer de um filho com deficiência acarreta consequências reais em seu desenvolvimento, é um feito singular na vida de seus pais que lidam com o combate entre o filho idealizado e o filho real. De acordo com Falkenbach et al (2008), a literatura evidencia que os integrantes da família, especificamente os pais, vivenciam emoções e confusões perante o diagnóstico de seu filho, como susto, pavor, culpa, revolta, denegação, ódio, rejeição, luto entre outros. Segundo Franco (2016) as famílias esperam, se preparam e constroem um filho antes de seu nascimento. Logo após da idealização, acontece o período que a família não encontra esperanças e ocorre a perda de expectativas, gerando aos progenitores a perspectiva de dar uma nova chance ao novo e a impensável realidade.

Conforme Sólcia (2004), os indivíduos de nossa sociedade não estão dispostos emocionalmente para serem pais por muitos motivos, como por exemplo, a ausência de exemplos de antecessores apropriados, a inexistência de normas recorrentes aos procedimentos e períodos do papel que devem cumprir, pela falta de maturidade individual e do casal, pela gestação não desejada, ocasionando a suspensão e modificação da rotina conjugal ou da família que irá receber a criança com deficiência.

De acordo com Glat (1989), ressalta que o nascimento de uma criança com deficiência, com individualidades diferentes do padrão imposto visto como o normal e a organização familiar se rompem, sentimentos desgastam, e se constitui um desequilíbrio na família. Que mesmo sendo unida, essa instabilidade é inelutável, pois o sonho construído diante a gestação, é desfeito. Ele destaca que é o mesmo que a família utópica construída por seus progenitores se encerra e a família da realidade deveria ser criada de imediato em suas mentes.

Conforme Silva (2009), a maioria dos pais, manifestam anseios de regularidade e evolução, ignorando a individualidade de cada deficiência. Portanto, é necessário dizer, que certas deficiências causam grandes limitações, propondo investimento afetivo, da família, trabalhista, e financeiras, para que ocorra o envolvimento da pessoa com deficiência e da família. Para que alcance o êxito é preciso permitir que o filho vivencie dificuldades e se frustre com os obstáculos do cotidiano, não realizando por ele o que ele pode vivenciar.

Segundo Gomes (2009), atualmente encontra-se obstáculos na sociedade contemporânea para inclusão e aceitação daqueles que possuem deficiência, a maioria das vezes a família é a confirmação desses obstáculos e dessa dificuldade encontrada atualmente.

Para Chacon (2011), o exagero de cuidado das famílias para com o filho com deficiência é prejudicial para o caminho do desenvolvimento, causando a dependência, lesando a evolução biopsicossocial dele. De acordo com Sales (2017) a forma que os progenitores tratam seus filhos, gera afeição do poder público e educadores, uma vez que há um cuidado para que as leis e normas sejam respeitadas, promovendo um avanço educacional, para que ocorra aos membros da família custeio aceitável que seja capaz de suprir as necessidades, objetivando que alcancem seus esforços e favoreça sua vida. 
De acordo com Casarin (1999), a organização da família se torna mais tranquila quando a um grande suporte entre o casal. Sendo assim, o meio familiar ajuda na evolução e avanço da criança e a família reconstitui sua instabilidade de forma distinta, em concordância com os recursos psicológicos que estão ao seu alcance.

Para Glat (1989), a crise entre os pais de uma criança com deficiência é inelutável, ocasionando a divisão do casal logo ao nascer do filho com deficiência, ideia defendida também por Blascovi (1997), ao afirmar que a saúde da relação do casal decai com o nascimento da criança e a frustração de ambos é um risco para a intimidade. Uma relação de forte intimidade consegue resolver os conflitos e as frustações da maternidade e paternidade.

Segundo Gomes (2009), atualmente encontram-se obstáculos na sociedade contemporânea para inclusão e aceitação daqueles que possui deficiência, a maioria das vezes a família é a confirmação desses obstáculos e dessa dificuldade encontrada atualmente. A relação família e escola colabora ricamente para o avanço da criança com deficiência no olhar de Lazzaretti e Freitas (2016), pois ambas constroem meios pertinentes para o bom aproveitamento e, desta forma, a interação ocorre de forma positiva, sendo o momento que estão unidas, não focam na deficiência, mas em suas competências, construindo pessoas com autoconfiança.

\section{Percurso Metodológico}

A pesquisa foi realizada no município de Passos localizado no interior do estado de Minas Gerais, na Mesorregião do Sul e Sudoeste de Minas. Com uma população estimada de 114.458 habitantes em agosto de 2017, distribuídos em uma área total de $1.339 \mathrm{~km}^{2}$ (CENSO, 2011). Segundo o Censo Escolar (2018), a cidade conta com vinte e uma escolas municipais, vinte estaduais e vinte e quatro privadas. Os participantes entrevistados foram dez famílias constituídas de pais de crianças diagnosticadas com deficiência, no município de Passos - MG, cujos dados foram coletados por meio de entrevistas com roteiro semiestruturado, com intenção de compreender as relações familiares, segundo o discurso dos pais (pai, mãe ou responsável). No momento das entrevistas os participantes não foram interpelados, seguindo a mesma ordem do roteiro, mas segundo os conteúdos e interesses que apareceram naquele instante. Os participantes foram identificados como: Entrevistada/Família 1,2,3,4,5,6,7,8,9,10 para que ocorresse o sigilo e a diferenciação de cada família entrevistada. Todos participantes foram esclarecidos a respeito da natureza da pesquisa e o Termo de Consentimento Livre e Esclarecido foi assinado por todos os participantes. As entrevistas foram gravadas, transcritas e analisadas à luz do referencial teórico proposto nessa pesquisa.

A análise das entrevistas foi utilizada para interpretar e compreender a visão do núcleo familiar, os diferentes contextos das famílias e sua relação para com o desenvolvimento das crianças com deficiência. A análise do discurso concebe a linguagem como mediação necessária entre o homem e a realidade natural e social analisa a relação estabelecida pela língua, entre os sujeitos que falam e as situações em que se produz o dizer. A análise aponta recortes que norteiam o principal foco, observando os principais pontos (SALLES; BARROS, 2009).

Foram entrevistadas dez famílias (pais, mães ou responsáveis) com pessoas deficientes do município de Passos-MG. A escolha do espaço físico foi muito importante para proporcionar acolhimento dos entrevistados. Foi necessária a escolha de um lugar calmo e com assentos para que os entrevistados se sentissem confortáveis. Utilizamos um gravador da marca Samsung Recorder MP3 2.6.3 para gravar o tempo necessário das entrevistas, o gravador esteve próximo do entrevistado e do entrevistador para alcançar todas as falas dos participantes sem distorção de áudio. A pesquisa foi submetida ao comitê de ética da UEMG e seguiu as normas definidas pela Resolução 466/12 do 
CNS/MS, destinada a pesquisas que envolvem seres humanos. Todos participantes foram esclarecidos a respeito da natureza da pesquisa. Foi realizado o Termo de Consentimento Livre e Esclarecido, onde todos os entrevistados leram e assinaram. Gravamos todas as entrevistas, transcrevemos e analisamos todos os dados fornecidos ao longo das respostas da pesquisa.

\section{Resultados e Discussão}

Foi possível perceber fortalezas e dificuldades das dez estruturas familiares entrevistadas e, para o melhor entendimento das informações, dividiram-se os dados em três categorias: o Contexto Financeiro, Relação Família e Deficiência e Convívio Escolar.

\section{Participantes}

As entrevistas foram realizadas com famílias em que as crianças com deficiências se encontram na faixa etária de 2 anos até 13 anos, nas quais duas se encontram em escolas privadas e oito em escolas municipais do município de Passos, sendo educação infantil e ensino fundamental I. Foram entrevistadas 10 famílias. No quadro abaixo é possível identificar informações dos pais, da criança e do tratamento.

\section{Quadro 1}

\begin{tabular}{|c|c|c|c|c|c|c|c|c|c|c|}
\hline Entrevistados & $\begin{array}{l}\text { Idade } \\
\text { dos } \\
\text { pais }\end{array}$ & Profissão & $\begin{array}{l}\text { Grau de } \\
\text { Instrução }\end{array}$ & $\begin{array}{l}\text { Estado } \\
\text { Civil }\end{array}$ & $\begin{array}{l}\text { Sexo da } \\
\text { criança }\end{array}$ & Idade & Série & Diagnóstico & Tratamento & Comorbidade \\
\hline Família 1 & $32 / 43$ & $\begin{array}{l}\text { Autônoma / } \\
\text { Motorista }\end{array}$ & Ensino Médio & $\begin{array}{l}\text { União } \\
\text { estável }\end{array}$ & M & 13 anos & 80 & $\begin{array}{l}\text { TDAH / Transtorno } \\
\text { mental e } \\
\text { comportamental - } \\
\text { déficit cognitivo }\end{array}$ & Ritalina & Nenhuma \\
\hline Família 2 & $39 / 39$ & $\begin{array}{l}\text { Dona de casa/ } \\
\text { Técnico de } \\
\text { Informática }\end{array}$ & $\begin{array}{c}\text { Ensino Médio/ } \\
\text { Primeiro } \\
\text { completo }\end{array}$ & Casado & M & $\begin{array}{l}2 \text { anos e } \\
3 \text { meses }\end{array}$ & $\begin{array}{c}\text { Ed. } \\
\text { Infantil }\end{array}$ & Autismo & $\begin{array}{c}\text { Terapia } \\
\text { ocupacional, } \\
\text { fono, ecoterapia, } \\
\text { psicomotricidade e } \\
\text { natação. }\end{array}$ & $\begin{array}{c}\text { Bronquite / asma } \\
\text { (prematuro } 34 \\
\text { semanas) }\end{array}$ \\
\hline Família 3 & $39 / 45$ & Aposentado & $\begin{array}{l}2^{\circ} \text { grau } \\
\text { completo }\end{array}$ & Casado & M & 12 anos & 50 & $\begin{array}{l}\text { Sangramento no } \\
\text { cérebro/ lleostomia }\end{array}$ & Psiquiatra & Nenhuma \\
\hline Família 4 & $29 / 31$ & $\begin{array}{l}\text { Dona do lar/ } \\
\text { Serviços Gerais }\end{array}$ & 20 grau & Casado & $\mathrm{F}$ & 4 anos & Pré I & $\begin{array}{l}\text { Meningomielocele / } \\
\text { Hidrocefalia }\end{array}$ & $\begin{array}{l}\text { APAE, ACED de } \\
\text { Poços de Caldas, } \\
\text { SARAH de Belo } \\
\text { Horizonte }\end{array}$ & Nenhuma \\
\hline Família 5 & $37 / 32$ & $\begin{array}{l}\text { Design de } \\
\text { Moda/ } \\
\text { Agropecuarista }\end{array}$ & $\begin{array}{l}\text { Superior } \\
\text { Completo }\end{array}$ & Casado & $\mathrm{F}$ & 4 anos & Prél & $\begin{array}{l}\text { Trissomia do } \\
\text { cromossomo } 21\end{array}$ & $\begin{array}{l}\text { APAE: fisioterapia, } \\
\text { fonoaudióloga, eco } \\
\text { terapia, psicóloga, } \\
\text { terapia ocupacional }\end{array}$ & Nenhuma \\
\hline Família 6 & $34 / 54$ & $\begin{array}{l}\text { Manicure/ } \\
\text { Vendedor }\end{array}$ & $\begin{array}{l}\text { Ensino Médio } \\
\text { Completo }\end{array}$ & $\begin{array}{l}\text { União } \\
\text { estável }\end{array}$ & M & 5 anos & Pré II & Autismo & $\begin{array}{c}\text { APAE: } \\
\text { fonoaudióloga, } \\
\text { psicóloga, terapia } \\
\text { ocupacional }\end{array}$ & Nenhuma \\
\hline Família 7 & $45 / 49$ & Dona de casa & $\begin{array}{l}\text { Ensino Médio } \\
\text { completo }\end{array}$ & Viúva & $\mathrm{F}$ & 4 anos & Pré I & $\begin{array}{l}\text { Agenesia do corpo } \\
\text { caloso }\end{array}$ & $\begin{array}{l}\text { APAE: psicóloga, } \\
\text { terapeuta. }\end{array}$ & Alergias \\
\hline Família 8 & $35 / 38$ & $\begin{array}{l}\text { Nutricionista/ } \\
\text { Professor }\end{array}$ & $\begin{array}{l}\text { Superior } \\
\text { Completo }\end{array}$ & Casado & M & 3 anos & Maternal I & T.E.A & $\begin{array}{c}\text { Psicoterapia } \\
\text { (ABA), T.O., Fono, } \\
\text { Equoterapia, } \\
\text { Psicopedagoga }\end{array}$ & Nenhuma \\
\hline Família 9 & $36 / 36$ & $\begin{array}{l}\text { Dona de casa/ } \\
\text { Líder de Vendas }\end{array}$ & $\begin{array}{l}\text { Superior } \\
\text { completo/ } \\
\text { Superior } \\
\text { Incompleto }\end{array}$ & Casado & M & 6 anos & Pré & Autismo & Fono, T.O, Psicóloga & Alergia Alimentar \\
\hline Família 10 & $37 / 40$ & $\begin{array}{c}\text { Vendedora/ } \\
\text { Gerente } \\
\text { Administrativo }\end{array}$ & $\begin{array}{l}\text { Primeiro Grau } \\
\text { completo }\end{array}$ & Casado & M & 10 anos & 40 ano & $\begin{array}{c}\text { Síndrome de } \\
\text { asperger (autismo } \\
\text { leve) }\end{array}$ & $\begin{array}{l}\text { Neurologista, } \\
\text { Fonoaudióloga e } \\
\text { Psicóloga }\end{array}$ & Nenhuma \\
\hline
\end{tabular}




\section{Contexto financeiro}

Os autores Carter e McCartthy (1995), afirmam que diante do nascimento de um filho com deficiência, são alterados os costumes habituais da família. A mãe acaba se afastando do emprego para dedicar mais tempo para os cuidados do filho, as condições financeiras sofrem reduções devido a esse afastamento, os gastos aumentam significativamente diante das quantidades de tratamentos, medicamentos e terapias que terão de ser realizadas durante toda a vida da criança.

As famílias 1, 4, 6 e 7 declararam renda familiar abaixo de dois salários, sendo majoritariamente com apenas um salário. Identificaram-se dificuldades diante da quantidade de tratamentos e remédios dispendiosos que a criança requer fato que é agravado pelo fato de as mães não poderem sair para trabalhar por terem que cuidar das necessidades dos filhos. Dessa forma somente com o salário do marido, aparecem as dificuldades financeiras. A entrevistada 8 , relatou que quando ocorreu o diagnóstico, ela e o esposo perceberam a necessidade de dedicar tempo ao filho, desse modo o marido que se dispôs a se ausentar do emprego para cuidar de seu filho e a mãe se ausentou apenas por sete meses do trabalho. As entrevistadas 2, 3, 5, 9 e 10 apresentam uma renda inferior ou igual a cinco salários, a entrevistada 8 a renda é superior a cinco salários. Na maioria a renda vem apenas do pai, porque a mãe prioriza o tempo para cuidar dos filhos, exceto a família 8 onde a mãe se dedica ao trabalho e o pai aos cuidados do filho. No caso das famílias com renda maior, muitos são os artifícios que os amparam, como: tratamentos, apoio de empregados, terapeutas, babas, psicólogos, e várias atividades que auxiliam no desenvolvimento de habilidades, que quando não trabalhadas não são desenvolvidas.

Na entrevista 1 a ausência do pai foi relatada. O pai não ajuda em nada dedicando seu tempo para o trabalho, assim podendo garantir o sustento familiar, trabalha de motorista durante todo o dia em uma empresa e à noite ele é motorista de entretenimento infantil e a mãe fica responsável por cuidar de todas as necessidades e cuidados da criança. Segundo Paniagua (2004) e Petean \& Suguihura (2005) na maioria das vezes as mães abandonam sua carreira profissional para se dedicar exclusivamente ao filho. Diante disso, como fuga, o pai se dedica ao trabaIho (PETEAN e SUGUIHURA, 2005). A entrevistada 7 o pai faleceu e a mãe ficou sozinha com a criança, onde a única renda é a pensão do falecido marido. Ela relata que sente muita falta do marido, já que com ele a família era unida, e hoje, mesmo tendo mais filhos, a família é apenas ela e a criança, pois os outros filhos, estão formando uma nova família, como a filha mais velha se casou e está gravida.

A família 4, retrata que enquanto a mãe se dedica a levar a criança para seus acompanhamentos, o pai trabalha com serviços gerais durante todo o dia e a noite ele cata latinha em bares e comércios para acrescentar na renda familiar, para poder comprar os medicamentos e alimentação correta, pois a ausência dos mesmos já prejudicou a criança, levando-a a internação. E a família 9, o pai se ausenta durante a semana, tendo contato com os filhos nos finais de semana, devido ao seu serviço que o cobra viagens para realizar vendas, por ser a única renda da família ele se dedica ao máximo.

A família 8, se queixa da falta de apoio financeiro do Estado, perante as famílias com filhos com deficiência, onde o auxílio do BPC (Benefício de Prestação Continuada) só beneficia famílias com renda mensal seja de até $1 / 4$ de salário mínimo por pessoa, ela julga que para conseguir esse benefício as pessoas precisam estar na linha da miséria, diz também que nessa situação a família não vai ter nem condições para se alimentar. Ela fala que esse benefício é incoerente, pois esse valor seria unicamente para suprir as necessidades básicas dessa pessoa com deficiência e não ser a renda mensal da família, pessoas com a renda um pouco maior do exigido não possuem direito ao benefício, sendo que os gastos são muitos e o salário é insuficiente para suprir todas as necessidades básicas essências da família, como: alimentação, higiene, tratamentos, terapias, medicamentos e outras. Segundo o portal do Governo brasileiro, possuem direito de receber o 
auxílio pessoas idosas com 65 anos ou mais e pessoas com deficiência, de qualquer idade, que tenham impedimentos de longo prazo. Os requerentes devem estar inscritos no Cadastro Único e ter renda familiar mensal inferior a 1/4 de salário mínimo vigente (BENEFÍCIO, 2019).

Diante dos relatos das entrevistadas, podemos observar que a renda familiar, após o nascimento de uma criança com deficiência, grande parte se compromete para os cuidados e necessidades dele. Na maioria das vezes, as mães saíram de seus empregos, se dedicando a cuidar dos filhos e suas limitações, onde o pai se dedica totalmente ao trabalho e pouco com os cuidados dos filhos. Algumas mães ainda se queixam de que seus maridos não ajudam em nada, além do financeiro, não as acompanham em médicos, terapias, tratamentos, entre outros. As famílias que apresentam maior renda, relataram diversos artifícios que contribuem para o desenvolvimento e a evolução da criança, sendo vários e diferenciados tipos de tratamentos, entre outros artifícios de custos altos. De certa forma contribuem para um melhor desenvolvimento da criança, as relações familiares se tornam mais tranquilas e seguras diante da deficiência, da relação com a criança e da inserção em sociedade.

\section{Relação família e deficiência}

O convívio familiar é de extrema importância para a evolução da criança com deficiência, além de ser assegurado por lei pela Constituição Federal art.227 que diz:

Art. 227. É dever da família, da sociedade e do Estado assegurar à criança, ao adolescente e ao jovem, com absoluta prioridade, o direito à vida, à saúde, à alimentação, à educação, ao lazer, à profissionalização, à cultura, à dignidade, ao respeito, à liberdade e à convivência familiar e comunitária, além de colocá-los a salvo de toda forma de negligência, discriminação, exploração, violência, crueldade e opressão (BRASIL, 2010).

Segundo Kaloustian (1988), a família tem papel importante na formação do indivíduo, sendo responsável pela transmissão de crenças, princípios, proteção, segurança. A partir da família que vai se formar uma visão de mundo e a construção das relações sociais.

As famílias 4, 5, 6 e 7 ao descobrirem sobre o diagnóstico de deficiência de seus filhos, os pais se assustaram, sentiram-se incapazes e com muito medo de não conseguirem atender as necessidades das crianças e inicialmente se viram despreparados. Todavia, aos poucos foram se instruindo melhor sobre as especificidades de cada deficiência, com o auxílio de profissionais da área, como médicos, psicólogos, terapeutas, professores de apoio, professores regentes de turma, entre outros. A partir disso, foram percebendo que essas circunstâncias aumentavam o vínculo de amor entre eles, o que foi capaz de transformar esse medo em força para enfrentar qualquer luta e dificuldade. De acordo com a sexta família a mãe relatou que de início ela teve muito medo, mas logo que começou a frequentar terapias e psicólogas, percebeu que seu filho evoluiu em diversos aspectos e a participação da família modificou diretamente o desenvolvimento de habilidades que ela nunca imaginou que ele seria capaz de realizar e atualmente vê que atividades simples que ela desempenha com ele em casa podem transformar seu aprendizado. Paniagua (2004) e Petean \& Suguihura (2005), relatam que no momento do nascimento, onde ocorre a descoberta da criança com deficiência, os pais se chocam, se responsabilizam pelo fato e sofrem pela quebra de idealização do filho perfeito. Na maioria das vezes os pais se sentem culpados por se sentirem incapazes e, geralmente, entram em depressão e em estado de luto.

Podemos observar pais mais maduros, com idade igual ou superior a 30 anos, todas as famílias entrevistadas relataram que foi planejado a gravidez da criança, na maioria dos casos foi o(a) primeiro(a) filho(a). As famílias 2 e 6 seus filhos apresentam TEA, onde na família 2 ambos os pais possuem idade igual, porém a mãe engravidou com 37 anos. Para Sandin et al. (2012) e Byars \& Boomsma (2016) relatado nas pesquisas de Maia et. al. (2018) quando a idade dos pais já está 
avançada o risco de TEA é maior. Já na família 6 há uma grande diferença de idade entre os pais, a mãe engravidou com 29 anos e o pai estava com 49 anos, o filho possui TEA. Segundo Parner et al (2012), quando a mãe apresenta idade inferior há 35 anos e o pai com idade superior as chances de desenvolver TEA também são significativas.

A sexta família enaltece a importância de mesmo após o diagnóstico da criança com deficiência, a relação marido e mulher deve se manter com muito dialogo e compreensão, pois a falta de companheirismo afasta o casal, pelo fato de que a esposa dedica a maior parte do tempo para cuidar das necessidades da criança e o marido se esforça para suprir a demanda financeira que passa a ser maior de acordo com a necessidade de tratamentos e cuidados de longo prazo. A oitava família relata que após o diagnóstico ocorre um desiquilíbrio familiar, tudo em prol da criança com deficiência, nesse momento o casal deixa de lado sua saúde, seu lazer, suas intimidas e dessa forma ela não considera sua família saudável, pois esse processo é muito estressante e desgastante, destacando também, que sua família está saturada. De acordo com Bee (2008) e Palácios (2004) ao nascer uma criança com deficiência a família passa por uma fase de adaptação, onde ocorre uma fase de transição, os pais precisam modificar a rotina conforme as especificidades da criança, o que altera a relação do casal, priorizando a relação entre pais e filhos, colocando a vida de casal em segundo plano o que acarreta discussões para a divisão de tarefas.

A entrevistada 8 se queixa de que:

\begin{abstract}
"são famílias, mães ou pais, ou mães sozinhas, ditas como especiais e ai dá a impressão assim, que você foi escolhido por Deus para uma missão incrível na terra e não é bem assim, a sociedade tem que ter o papel dela, o Estado tem que ter o papel dele, e todos tem o seu papel perante aquele cidadão que tem uma deficiência, então não é papel da família ter essa missão especial pra cuidar dessa criança sozinha, porque é muito estressante, sobrecarrega, as vezes tem mães que cuidam sozinha e anulam sua vida ... tirar um pouco esse negócio de anjo azul, mãe especial, parece assim que desumaniza, a partir do momento que você desumaniza a pessoa parece que ela tem assim, é uma missão, e não, ela tem direitos, ela tem direitos perante a sociedade e isso tem que ser respeitado" em contrapartida a família 10 defende o fato de que "uma criança assim especial, ela só vem para quem merece, ter a capacidade de ter e elas vem justamente pra ter um propósito na vida, Deus põe, então isso ai me marcou muito" (FAMÍLIA 8)
\end{abstract}

Diferentes mães com filhos com a mesma deficiência, apresentam opiniões contrárias diante da subjugação de famílias especiais, mães especiais e filhos especiais.

Vimos que o convívio familiar representa papel fundamental para o desenvolvimento da criança com deficiência, além de proporcionar segurança e cuidado. Mas nota-se que não é tão simples assim, pois, no começo, a família tem receios de como cuidar, medo de não conseguir, pouca instrução, geralmente se culpam e se queixam do afastamento da intimidade do casal e a mudança da rotina. Buscando forças para superar essa fase de aceitação, se apoiam no amor, se reestruturam e buscam apoio de profissionais capacitados na área. Algumas mães se sentem especiais, outras, porém, se queixam dizendo que essa missão não pertence somente à família, mas a toda sociedade.

Na Relação Família e Deficiência observamos que as famílias apresentam pensamentos distintos diante de sua realidade, algumas famílias apresentaram aspectos de aceitação em suas falas, já outras questionam a forma que a sociedade enxerga a deficiência, dita com um presente para a família especial, pais especiais, e não concordam com o pensamento, pois a muitos conflitos e complicações como: preconceitos, afastamento da intimidade do casal, a mudança da rotina, mudança de configuração de marido, para pai e marido, de esposa para esposa e mãe de uma criança com deficiência, deixando seus sonhos e planos para priorizar os cuidados. 


\section{Convívio Escolar}

A inclusão escolar é direito das pessoas com deficiência, no Art. 27 da Lei no13.146 de 06 de Julho de 2015 diz que:

Art. 27. A educação constitui direito da pessoa com deficiência, assegurados sistema educacional inclusivo em todos os níveis e aprendizado ao longo de toda a vida, de forma a alcançar o máximo desenvolvimento possível de seus talentos e habilidades físicas, sensoriais, intelectuais e sociais, segundo suas características, interesses e necessidades de aprendizagem (BRASIL, 2015).

Porém algumas entrevistadas se queixaram do despreparo das escolas e dos professores para receber as crianças com deficiência, e a falta de adaptações para suprir as suas necessidades, como: adaptações pedagógicas, didáticas e socialização. Na visão da família, é necessário preparo dos profissionais e consciência da sociedade perante os cuidados para com as especificidades de cada deficiência, destacando a importância do amor pela profissão, também dizem que os professores deveriam receber e tratar todos os seus alunos, especialmente os com deficiência, como se fossem seus filhos. Brito \& Dessen et al. (1999), Falkenbach et al (2008) e Souza \& Boemer (2003) relatam que apesar do grande número de crianças com deficiência nas escolas, elas ainda são vítimas de preconceitos frequentemente em nossa sociedade, por serem consideradas fora de um padrão e não atenderem ao ritmo desejado de desenvolvimento, são deixados de lado e excluídos. Entretanto as famílias 8, 9 e 10 estão satisfeitas com o tratamento e 0 cuidado que as escolas proporcionam aos seus filhos, a única falha observada pela família 8 é a ausência do feedback, pois a mãe relata que ela precisa ser informada de todos os detalhes da rotina escolar de seu filho.

Um fator que deixa as mães preocupadas é o bullying nas escolas. Na família 4 a mãe chegou a relatar que ela mesma já sofreu bullying por apenas mancar e tem muito medo da sua filha sofrer, por se locomover através de uma cadeira de rodas. A entrevistada 2 fala que não pretende mais colocar o seu filho na escola e se for preciso irá lutar na justiça, devido ao fato de várias mães de crianças com deficiência relatarem a ela, episódios de violência, maus tratos e descasos, de até mesmo professores de apoio para com o desenvolvimento de seus filhos. De acordo com Paniagua (2004), na fase de transição, momento no qual a criança começa a frequentar a escola, os pais não se sentem seguros e receiam que seus filhos não tenham o cuidado devido e que sofram com preconceito.

Nota-se que as famílias ainda possuem muito receio em deixar seus filhos com deficiência na escola, devido ao medo de sofrerem preconceitos, bullying e de serem excluídos por não se encaixarem no padrão estipulado pela sociedade, reflexos esses vindos desde a antiguidade. Ainda lamentam pelo despreparo dos profissionais e a falta de adaptações pedagógicas e didáticas para suprir as limitações de seus filhos. São poucas as mães, que se sentem seguras ao deixarem seus filhos na escola, quando encontram uma escola que se sentem seguras se apoiam e quando é necessária mudança escolar, esse medo retoma. O Convívio Escolar, apesar de garantido por lei, algumas famílias se revoltam dizendo que mesmo assim ainda é preciso muito luta para conseguir oportunidades em escola de qualidade, onde seus filhos serão vistos com respeito, dignidade e tenham suas necessidades supridas.

\section{Considerações Finais}

Esse trabalho foi realizado com a finalidade de compreender e analisar o contexto familiar de dez famílias, a fim de observar os principais pontos de dificuldades e seus pareceres perante a deficiência de seus filhos. Nota-se a importância da estrutura familiar no desenvolvimento e evolução da criança com deficiência e diante das análises foi possível perceber os fatores que 
mais se destacaram diante das entrevistas realizadas. Dentre eles estão o Contexto Financeiro, Relação Família e Deficiência e Convívio Escolar.

A família é a base dessas crianças e, diante disso, as atitudes em relação a elas são espelhadas e reproduzidas em forma de valores, portanto a maneira que a família se expressa e se relaciona é fundamental para o desenvolvimento e autonomia, para que a partir da primeira instituição de sua vida - a família - ela esteja preparada para o processo de inclusão em sociedade, perante as dificuldades que serão enfrentadas diariamente. Vale ressaltar a importância de uma formação continuada dos profissionais que estão, diretamente e indiretamente, ligadas às crianças com deficiência, que se habilitem para transformar vidas e para que entendam as dificuldades e complicações encontradas por trás da realidade de cada criança, suas bagagens e histórias de vida.

É importante o investimento em mais pesquisas na área para contribuir e acrescentar na capacitação e empenho de toda a sociedade, perante a deficiência. Acreditamos que, a partir dessa pesquisa, foi possível contribuir de forma positiva para que outras famílias tenham conhecimento de vivências e experiências, similares as suas. Portanto, interessou-nos contribuir como subsídio para futuros pesquisadores no âmbito na educação especial e inclusiva, bem como para os professores, educadores e demais profissionais da área educacional.

\section{Referências}

BEE, Helen. A criança em desenvolvimento. Porto Alegre: Artmed. 2008. Disponível em: <https://edisciplinas.usp.br/pluginfile.php/3226130/mod_resource/content/1/Livro\%20 -\%20A\%20criança\%20em\%20desenvolvimento\%20-\%20Bee.pdf> Acesso em: 20 de jun, de 2019.

BENEFÍCIO, de Prestação Continuada. Governo do Brasil. 2019. Disponível em: <http://mds.gov. $\mathrm{br} /$ acesso-a-informacao/mds-pra-voce/carta-de-servicos/usuario/assistencia-social/bpc> Acesso em: 03 de set de 2019.

BLASCOVI-ASSIS, S. M. Lazer e deficiência mental. Campinas, SP: Papirus,1997. Disponível em: <http://repositorio.unicamp.br/bitstream/REPOSIP/275283/1/Blascovi-Assis_SilvanaMaria_D. pdf> Acesso em: 25 de julho de 2019.

BONILHA, Fabiana. A deficiência sensorial. Correio Popular, 2013. Disponível em: <https://correio.rac.com.br/_conteudo/2013/12/capa/projetos_correio/e_braille/ponto_ de_vista/132701-a-deficiencia-sensorial.html> . Acesso em: 31 jul. 2019.

BRASIL. Art. 27 da Lei no 13146 de 06 de Julho de 2015. Estatuto da Pessoa com Deficiência. Disponível em: <https://www.jusbrasil.com.br/topicos/49549873/artigo-27-da-lei-n-13146de-06-de-julho-de-2015> Acesso em: 29 de set. de 2019.

BRASIL. Art. 227 Constituição Federal de 88. Constituição da República Federativa do Brasil. Brasília, DF. Redação dada Pela Emenda Constitucional no 65. 2010. Disponível em: <https://www.jusbrasil.com.br/topicos/10644726/artigo-227-da-constituicaofederal-de-1988> Acesso em: 29 de set. de 2019.

BRASIL. Direito à educação: subsídios para a gestão de sistemas educacionais: orientações gerais e marcos legais. Brasília: Ministério da Educação, Secretaria de Educação Especial. 20 ed. 2006. Disponível em: <http://portal.mec.gov.br/seesp/arquivos/pdf/direitoaeducacao. pdf> Acesso em: 20 de set. 2019. 
BRITO, A. M. W., \& DESSEN, M. A. Crianças surdas e suas famílias: um panorama geral. Psicologia: Reflexão e Crítica, 12(2), 1-11. 1999. Disponível em: <https://www.passeidireto. com/arquivo/28538635/bock-a-m-b-furtado-o-teixeira-m-l-t-psicologias-uma-introducaoao-estudo-de-psicologia-sao-paulo-saraiva-2002-pp-18-43-pdf> Acesso em: 30 de set. 2019.

BYARS SG; BOOMSMA JJ. Opposite differential risks for autism and schizophrenia based on maternal age, paternal age, and parental age differences. Evol Med Public Health; 2016:286-98. 2016. Disponível em:< https://www.docsity.com/pt/leo-buscaglia-osdeficientes-e-seus-pais/4808022/> Acesso em: 30 de julho 2019.

CARTER, R. e McCARTTHY, Michael. As mudanças no ciclo de vida familiar: uma estrutura para a terapia familiar. Artes Médicas, 1995. Disponível em: <https://www.amazon.com.br/ Mudan\%C3\%A7as-Ciclo-Vida-Familiar-Estrutura/dp/8573078332> Acesso em: 5 de junho 2019.

CASARIN, S. Aspectos psicológicos na síndrome de Down. Em J.S. Schwartzman (Org.). Síndrome de Down. São Paulo: Mackenzie, p. 263-285. 1999.Disponivel em: < https://www.passeidireto. com/arquivo/5974713/familia_sindrome_down/5> Acesso em: 15 de julho 2019.

CENSO, Demográfico. Características da População e dos Domicílios. Resultados do Universo. Ministério do Planejamento, Orçamento e Gestão. Instituto Brasileiro de Geografia e Estatística - IBGE. Rio de Janeiro. 2011. Disponível em: <https://biblioteca.ibge.gov.br/visualizacao/ periodicos/93/cd_2010_caracteristicas_populacao_domicilios.pdf>. Acesso em: 20 de jul. 2019.

CENSO, Escolar. Resumo Técnico Censo da Educação Básica 2018. Diretoria de Estatísticas Educacionais DEEP. Instituto Nacional de Estudos e Pesquisas Educacionais Anísio Teixeira INEP. Ministério da Educação MEC. Brasília. ISBN: 978-85-7863-070-6. 2018. Disponível em:<http://download.inep.gov.br/educacao_basica/censo_escolar/resumos_tecnicos/ resumo_tecnico_censo_educacao_basica_2018.pdf $>$. Acesso em: 20 jul. 2019.

CHACON, M.C.M. Aspectos relacionais, familiares e sociais da relação pai-filho com deficiência física. Revista Brasileira de educação especial. Marília-SP, v.17, n.3 Marília Sept./Dec. 2011.Disponivel em: <http://www.scielo.br/scielo.php?script=sci_arttext\&pid= S1413-65382011000300007> Acesso em: 16 de setembro 2019.

CONVENÇÃO da ONU sobre os Direitos das Pessoas com Deficiência. Acessibilidade Brasil, 2008. Disponível em: <http://www.acessibilidadebrasil.org.br/joomla/destaquesacessibilidade/124-convencao-da-onu-sobre-os-direitos-das-pessoas-com-deficiencia>. Acesso em: 31 jul. 2019.

DEFICIÊNCIA física: conheça os tipos, as causas e os fatores de risco. Centro de Estudos e Formação. 2017. Disponível em: https://www.centrodeestudoseformacao.com.br/blog/ deficiencia-fisica-curso-online. Acesso em: 31 jul. 2019.

DESSEN, Maria Auxiliadora; POLONIA, Ana da Costa. A família e a escola como contextos de desenvolvimento humano. Universidade de Brasília, 2007. Disponível em: <http://www. scielo.br/pdf/paideia/v17n36/v17n36a03.pdf > Acesso em: 27 de jul. de 2019.

DIAS, Sueli de Souza; OLIVEIRA, Maria Cláudia Santos Lopes. Deficiência intelectual na perspectiva histórico-cultural: contribuições ao estudo do desenvolvimento adulto. Revista Brasileira de Educação Especial, [s.l.], v. 19, n. 2, p.169-182, jun. 2013. Disponível em: <http://www.scielo.br/scielo.php?pid=S1413-65382013000200003\&script=sci_abstract\& tlng=pt> Acesso em: 30 de jul. 2019. 
FALKENBACH, A. P.; DREXSLER, G.; WERLER, V. A relação mãe/criança com deficiência: Sentimentos e experiências. Ciência \& Saúde Coletiva, p. 2065-2073. 2008.Disponivel em: $<$ https://www.researchgate.net/publication/250028257_A_relacao_maecrianca_com_ deficiencia_sentimentos_e_experiencias> Acesso em: 24 de junh. de 2019.

FRANCO, Vitor. Tornar-se pai/mãe de uma criança com transtornos graves do desenvolvimento. Educar em Revista, Curitiba, PR, v. 1, n. 59, p. 35-48, jan./mar. 2016. Disponível em: <http://www.scielo.br/pdf/er/n59/1984-0411-er-59-00035.pdf> Acesso em: 15 de set. 2019.

GLAT, Rosana. 0 papel da família na integração do portador de deficiência. Revista Brasileira de Educação Especial, p. 111-118. 1996. Disponível em: <https://www.abpee.net/homepageabpee04 _06/artigos_em_pdf/revista4numero1pdf/r4_art09.pdf> Acesso em: 20 de ago. 2019.

GLAT, Rosana. Somos iguais a vocês: depoimentos de mulheres com deficiência mental. Rio de Janeiro: Editora Agir, 1989. Disponível em: < https://www.skoob.com.br/livro/pdf/ somos-iguais-a-voces/livro:533780/edicao:542507> Acesso em: 25 de jun. 2019.

GOMES, Maria de Fátima Canuto. Papel da Família na Inclusão de Alunos portadores de deficiência auditiva: Estudo de Caso na escola básica Eugénio Tavares. Dissertação: Universidade Jean Piaget de Cabo Verde, 2009. Disponível em: <https://core.ac.uk/download/ pdf/38682333.pdf>. Acesso em: 25 de ago. 2019.

HENN, C. G.; PICCININI, C. A.; GARCIAS, G. L. A família no contexto da síndrome de down: revisando a literatura. Psicologia em Estudo, 13, 3, 485-493. 2008. Disponível em: <http://www.scielo.br/pdf/pe/v13n3/v13n3a09.pdf> Acesso em: 25 de ago. 2019.

IDMED. Doença Mental e Intelectual. IDMED São Paulo, jun. 2014 Disponível em: <http://idmed.com.br/Sa\%C3\%BAde/Sa\%C3\%BAde-Mental/doencamental-e-intelectualsaiba-a-diferenca.html> Acesso em: 31 jul. de 2019.

KALOUSTIAN, S. M. Família Brasileira, a Base de Tudo. São Paulo: Cortez; Brasília, DF: UNICEF, 1988. Disponível em:<https://www.estantevirtual.com.br/livros/silvio-manoug-kaloustian/ familia-brasileira-a-base-de-tudo/3984767496> Acesso em: 15 de ago.2019.

LAZZARETTI, Beatriz; FREITAS, Alciléia Sousa. Família e Escola: O processo de inclusão escolar de crianças com deficiências. Caderno Intersaberes. vol. 5, n.6, p.1-13. ISSN 2317 - 692x. 2016. Disponivel em: <https://pt.scribd.com/document/389278035/376-501-1-PB>. Acesso em: 10 de ago.2019.

MAIA, Fernanda Alves et al. Transtorno do espectro do autismo e idade dos genitores: estudo de caso-controle no Brasil. Cadernos de Saúde Pública. v. 34, n. 8, p.1-14. Rio de Janeiro. 2018. Disponível em:<http://dx.doi.org/10.1590/0102-311x00109917> Acesso em: 24 de ago. de 2019.

PALÁCIOS, J. Mudança e desenvolvimento durante a idade adulta e a velhice. Em C. Coll, A. Marchesi \& J. Palácios (Orgs.), Desenvolvimento psicológico e educação - Psicologia evolutiva (pp. 371-388). Porto Alegre: Artmed. 2004. Disponível em: < https://www.larpsi.com.br/ media/mconnect_uploadfiles/c/a/cap_01_79_.pdf> Acesso em: 23 de ago. 2019.

PANIAGUA, G. As famílias de crianças com necessidades educativas especiais. Em C. Coll, A. Marchesi \& J. Palácios (Orgs.), Desenvolvimento psicológico e educação: transtornos do desenvolvimento e necessidades educativas especiais (pp. 330- 346). Porto Alegre: Artmed. 2004. Disponível em: <http://www2.fc.unesp.br/cbe/IVCBE-Vol-02.pdf> Acesso em: 21 de set. 2019. 
PARNER E.T; BARON-COHEN S; LAURITSEN M.B; JORGENSEN M; SCHIEVE L.A; YEARGIN-ALLSOPP M, et al. Parental age and autism spectrum disorders. Ann Epidemiol; 22:143-50. 2012. Disponível em: < https://www.ncbi.nlm.nih.gov/pubmed/22277122> Acesso em: 13 de jun. 2019.

PETEAN, E. B. L. \& SUGUIHURA, A. L. M. Ter um irmão especial: convivendo com a Síndrome de Down. Revista Brasileira de Educação Especial, 11(3), 445-460. 2005. Disponível em: <http://www.scielo.br/pdf/rbee/v11n3/v11n3a09.pdf> Acesso em: 28 de julh.2019.

SALES, Felipe. A influência Familiar no desenvolvimento das pessoas com deficiência. Revista Eletrônica de Ciências da Educação. ISNN: 1677 3098. v.16, n. 1 e 2. 2017. Disponível em: <http://www.periodicosibepes.org.br/index.php/reped/article/view/2360> Acesso em: 26 de jul. de 2019.

SALLES, Mariana Moraes; BARROS, Sônia. Vida cotidiana após adoecimento mental: desafio para atenção em saúde mental. Acta Paulista de Enfermagem, vol. 22, núm. 1, enerofebrero, pp. 11-16. Escola Paulista de Enfermagem. São Paulo, Brasil. 2009. Disponível em: <https://www.redalyc.org/pdf/3070/307026616003.pdf> Acesso em: 21 de set. de 2019.

SANDIN S; HULTMAN C.M.; Kolevzon A; Gross R; MacCabe JH; Reichenberg A. Advancing maternal age is associated with increasing risk for autism: a review and meta-analysis. J Am Acad Child Adolesc Psychiatry. 51:477-86.e1. 2012. Disponível em:< https://www.ncbi.nlm. nih.gov/pubmed/22525954> Acesso em: 28 de ago. 2019.

SILVA, S. B.O. Autismo e as transformações na família. Monografia apresentada como requisito parcial para a obtenção do título de Bacharel em Psicologia da Universidade do Vale do Itajaí, Santa Catarina, 2009. Disponível em:<http://siaibib01.univali.br/pdf/scheila\%20borges\%20 da\%20silva.pdf> Acesso em: 08 de out. 2019.

SÓLCIA, I. V. Âmbito familiar: a reação da família frente a notícia da deficiência dos filhos. Monografia apresentada na Universidade Estadual do Norte do Paraná. 2004. Disponível em: <https://monografias.ufrn.br/jspui/bitstream/123456789/2587/1/ANA_MARAISE_TCC_ VERSAO_FINAL_OK.pdf> Acesso em: 04 de set. 2019.

SOUZA, L. G. A.; BOEMER, M. R. O ser - com o filho com deficiência mental - alguns desvelamentos. Paidéia, 13(26), 209- 219. 2003. Disponível em: < http://www.scielo.br/pdf/ paideia/v13n26/10.pdf> Acesso em: 15 de set. 2019. 